\title{
A cascaded multilevel inverter topology with only one bidirectional conducting switch
}

\begin{abstract}
The most common multilevel inverter topology types are neutral point clamped or diode clamped inverter, flying capacitor inverter and cascaded H-bridge inverter. Among the three, the cascaded H-bridge inverter is becoming the most popular type of multilevel inverter as the world is moving towards renewable energy. The cascaded H-bridge has modular structure, so it can be easily adapted in multiple dc sources system such as photovoltaic systems. The main disadvantage of cascaded $\mathrm{H}$-bridge inverter is it requires a high number of switches, particularly for a high number of output voltage levels design. Another major disadvantage is a high number of switches need to be turned on during cascaded H-bridge operation, thus accumulating voltage drops across the conducting switches before it reach the output terminals, resulting losses and reduced efficiency, especially for a high power installation. In this paper, an uninterrupted neutral line multilevel inverter topology with only one conducting bidirectional switch at any time of operation is proposed. A 41-level version of the proposed topology is constructed and tested in Matlab Simulink platform. The result shows that for a high output voltage levels and high power load, the proposed inverter has a very low output THD level and a minimum internal losses.
\end{abstract}

Keyword: Cascaded multilevel inverter; Conducting switch; High power inverter; Uninterruptible neutral line; Renewable energy; Low THDcomponent 